NASA Technical Memorandum 106419 AIAA-93-1899

\title{
Investigation of a Subsonic-Arc-Attachment Thruster Using Segmented Anodes
}

Darren H. Berns

University of Minnesota

Minneapolis, Minnesota

and

John M. Sankovic and Charles J. Sarmiento

Lewis Research Center

Cleveland, Ohio

Prepared for the

29th Joint Propulsion Conference and Exhibit

cosponsored by the AIAA, SAE, ASME, and ASEE

Monterey, California, June 28 -30, 1993

\section{N/SN}




\title{
INVESTIGATION OF A SUBSONIC-ARC-ATTACHMENT THRUSTER USING SEGMENTED ANODES
}

\author{
Darren H. Berns* \\ University of Minnesota \\ Minneapolis, MN 55455
}

and

John M. Sankovic** and Charles J. Sarmiento ${ }^{\dagger}$

National Aeronautics and Space Administration

Lewis Research Center

Cleveland, $\mathrm{OH} 44135$

\begin{abstract}
$\underline{\text { Abstract }}$
To investigate high frequency arc instabilities observed in subsonic-arc-attachment thrusters, a $3 \mathrm{~kW}$, segmented-anode arcjet was designed and tested using hydrogen as the propellant. The thruster nozzle geometry was scaled from a $30 \mathrm{~kW}$ design previously tested in the 1960's. By observing the current to each segment and the arc voltage, it was determined that the $75.200 \mathrm{kHz}$ instabilities were results of axial movements of the arc anode attachment point. The arc attachment point was fully contained in the subsonic portion of the nozzle for nearly all flow rates. The effects of isolating selected segments were investigated. In some cases, forcing the arc downstream caused the restrike to cease. Finally, decreasing the background pressure from $18 \mathrm{~Pa}$ to $0.05 \mathrm{~Pa}$ affected the pressure distribution in the nozzle, including the pressure in the subsonic arc chamber.
\end{abstract}

\section{Introduction}

The arcjet thruster uses an electric arc to increase the enthalpy of the propellant. By heating the gas directly, gas temperatures exceeding the engine component material limits can be obtained. Arcjets were first evaluated as propulsion sources in the late 1950's. A large development effort continued until the mid1960 's and centered on a $30 \mathrm{~kW}$ primary propulsion mission. Two main arcjet design concepts resulted. The first used a Laval anode/nozzle with a conical converging side, a short cylindrical throat, and a conical diverging section. The arc passed through the throat and attached in the supersonic divergent section. 1 The second thruster design incorporated a nozzle consisting of a long cylindrical section upstream of a conical Laval nozzle. In that thruster the arc attached in the subsonic cylindrical section. 2 Schematics of both nozzle designs along with a summary of the early hydrogen arcjet development effort are provided by Sankovic, $e t$ al. 3 Because of the lack of a $30 \mathrm{~kW}$ space power source, the early arcjet program ended in the mid1960 's. During that time period, a limited effort was expended on developing a 1-kW-class, supersonic-arc-attachment, hydrogen arcjet for stationkeeping. Although some performance data were obtained, non-erosive starting techniques and long life were never demonstrated before program termination. 4

In the early 1980 's low-power, supersonic-arcattachment arcjets were reexamined for stationkeeping applications. The propellant chosen was hydrazine due to availability aboard existing geostationary spacecraft. By 1987 most life and starting issues at a performance level of $450 \mathrm{~s}$ specific impulse had been solved, and a $1000 \mathrm{~h} / 500$ cycle life test at $1.4 \mathrm{~kW}$ was completed by Curran and Haag. 5 Under a NASA contracted effort, Rocket Research Co. (RRC) developed a $2.0 \mathrm{~kW}$ hydrazine arcjet system with a nominal mission average specific

\footnotetext{
${ }^{*}$ Graduate Student, Department of Mechanical Engineering

** Aerospace Engineer, On-Board Propulsion Branch, Member AIAA

$\dagger$ Electrical Engineer, On-Board Propulsion Branch
} 
impulse of 502 s. 6 That system has recently been flight qualified and is currently baselined on several geostationary communication satellite series including Telstar IV, Intelsat 8, AsiaSat, and EchoStar.

The use of high-power arcjets for primary propulsion was also given a new look in the mid-1980's. The Air Force has baselined ammonia arcjets for both its ESEX and ELITE flight experiments. ${ }^{7}$ In support of those programs the Jet Propulsion Laboratory has completed a $1460 \mathrm{~h}$ endurance test at $10 \mathrm{~kW}$ on ammonia. 8 NASA and the SDIO have pursued high-power hydrogen arcjets for orbit transfer applications. The result was the development of a $10 \mathrm{~kW}$ power processor which has been successfully integrated with a hydrogen arcjet. 9 Preliminary performance data have been obtained on high-power, hydrogen, supersonic-arcattachment thrusters, but the current performance is significantly below that obtained in the 1960's on similar devices. 10 Rocket Research Co., under SDIO support, investigated the performance of a $10 \mathrm{~kW}$, subsonic-arc-attachment thruster scaled from a 1960's design. The efficiency of the device was over $40 \%$ at specific impulse levels below $900 \mathrm{~s}$, but dropped rapidly as $1000 \mathrm{~s}$ specific impulse was approached. 11 Recently, using dimensions and schematics from the 1960 's, the $30 \mathrm{~kW}$, regeneratively-cooled, subsonic-arc-attachment thruster was fabricated and tested to determine if the RRC results at 10 $\mathrm{kW}$ were due to scaling. Unfortunately, the efficiency values obtained were near $45 \%$, significantly below the value of $55 \%$ reported in earlier reports. 12 At this time the cause of the discrepancy is unknown. Even at $45 \%$, the efficiency was still higher at some specific impulse levels than current supersonic-arcattachment designs. Because of the lack of data at low powers and the desire to obtain data at low facility background pressures, it was decided to investigate the performance of a nominally $3 \mathrm{~kW}$ device geometrically-scaled from the 1960's 30 $\mathrm{kW}$ thruster. The operational characteristics and performance of the device are reported in a companion paper. 13

During the performance testing of the $3 \mathrm{~kW}$ device, several voltage instability modes were discovered. It was believed that the oscillations were caused by movement of the arc anode attachment point. To investigate the phenomenon, a segmented-anode version of the thruster was fabricated and tested. The nozzle was divided into five segments and the current to each was monitored. With the ability to monitor the current to different areas of the anode, it was possible to determine if the arc attachment point was indeed in the subsonic cylindrical section upsteam of the Laval nozzle. The effects of flow rate on the anode current distribution were observed. With the capability to electrically isolate each anode segment, the effect of forcing the arc downstream was investigated. Finally, pressure taps were placed in two of the segments and changes in thruster operating parameters due to varying the facility background pressure were noted.

\section{Experimental Apoaratus}

\section{Arcjet Thruster and Segmented Anode}

A modular, low-power design developed by NASA LeRC and used in previous testing 14 was incorporated here. Figure 1 shows a schematic of the thruster while Figure 2 is a detailed illustration of the electrode region. The segmented anode shown in Figure 2 has the same overall dimensions as the solid anode used in the companion paper by Sankovic and Berns. 13 However, the anode used here was divided into five segments separated by thin electrically insulating disks. The design of these segments and their fixture were similar to those used in a segmented anode study by Curran, et al. 15 The segments were numbered consecutively, beginning with the upsteam segment. The first and fifth segments were made of $2 \%$ thoriated tungsten, while the second, third and fourth segments were fabricated out of tantalum. Tantalum was used for the inner segments due to fabrication issues. Segment 4 contained the throat region of the nozzle along with the 45 degree convergence to the throat upstream and the beginning of the 15 degree downstream divergence. Segments 1,2 , and 3 comprised the upstream subsonic portion, while segment 5 contained most of the downstream supersonic region.

The electrical insulators where machined from high-purity boron nitride. They contained two concentric regions, the inner portion was 0.025 $\mathrm{cm}$ wide, while the outer portion was $0.076 \mathrm{~cm}$ wide. Alignment of the segments and insulators was accomplished by the use of recesses on both the insulators and the segments. Electrical connections to segments 1 and 5 were made by contacting the flanges which held these segments in place. Electrical connections to segments 2, 3 , and 4 were made by attaching to a tab machined off of each segment. A second set of 
segments 3 and 4 were also used. All dimensions were exactly the same as shown in Figure 2, but pressure taps were installed into the center of each segment. The pressure tap consisted of a small hole and a pressfit tube connector. A $0.025 \mathrm{~cm}$ diameter hole which extended from the nozzle approximately $0.13 \mathrm{~cm}$ into the segment. The hole was then connected to a $0.18 \mathrm{~cm}$ diameter tube which was pressfit into the segment. The alignment of the individual segments was very good as shown by Figure 3. The entire anode assembly shown in Figure 1 was held together by a flange surrounding segment 5 . The flange was held firm by four rods and Inconel springs. Tangential flow injection was used, and propellant sealing was provided by graphite foil gaskets. The arc gap was set by retracting the cathode $0.058 \mathrm{~cm}$ from contact with the anode.

\section{Eacility}

Power processing was provided by a $5 \mathrm{~kW}$ output dc-dc converter with pulse starting circuit developed by Gruber, et al. 16 The thruster was contained in a $1.5 \mathrm{~m}$ diameter, $5 \mathrm{~m}$ long vacuum chamber pumped by four $0.82 \mathrm{~m}$ oil diffusion pumps each with a rated capacity of approximately $32 \mathrm{~m}^{3} / \mathrm{s}$ at $19 \mathrm{~Pa}$. The diffusion pumps were backed by a $0.61 \mathrm{~m} 3 / \mathrm{s}$ rotary blower and two $0.14 \mathrm{~m}^{3} / \mathrm{s}$ roughing pumps. The diffusion pumps were not used for some tests, since the propellant flow rates exceeded the rated capacity. For $10 \mathrm{mg} / \mathrm{s}$ hydrogen flow the facility pressure with the diffusion pumps was $0.05 \mathrm{~Pa}$, and with only mechanical pumps the pressure was $18 \mathrm{~Pa}$. At flow rates greater than $10 \mathrm{mg} / \mathrm{s}$, all data reported were taken without the diffusion pumps.

\section{Electrical and Pressure Configuration}

Figure 4 shows the electrical configuration used. The arrangement is the same as used in previous segmented anode testing. 15 Each segment had the capability of being electrically conducting or isolated. The connection of the anode segments to the power processing unit (PPU) was controlled by a set of five manual switches. A separate Hall effect current probe was connected to each segment. The output from each probe was sent to two four-channel digital oscilloscopes and to an eight channel strip chart recorder. The arcjet voltage measured across the PPU was also sent to the digital oscilloscope and the strip chart recorder. The digital oscilloscope offered high temporal resolution for analysis of high frequency fluctuations, while the strip chart recorder captured lower frequency changes. These data were synchronized and used to monitor the current through each segment and the total voltage across all segments.

A schematic of the pressure measurement apparatus is also shown in Figure 4. The upstream pressure tap was connected to a 0-103.4 $\mathrm{kPa}$ absolute pressure transducer. The downstream tap was connected to a $0-6.89 \mathrm{kPa}$ gauge pressure transducer. The transducers were supported inside of the vacuum facility with vacuum as the reference pressure. Each transducer output signal was then connected to a separate power supply and signal conditioning electronics, located outside of the vacuum facility. From the signal conditioning electronics, the pressure signals were sent to a strip chart recorder.

\section{Instrumentation and Calibration}

Operational data were recorded using the microcomputer-based data acquisition system (DACS) described in Reference 17. The computer monitored propellant flow rate, total current, total voltage, thruster temperature, and propellant feed pressure. The total output current from the PPU was measured using a calibrated shunt. The total voltage measurement was taken at the power connector feedthrough on the vacuum facility. Both $0-30$ SLPM and 0-10 SLPM thermal-conductivity type flow controllers were used to regulate gas flow rates. The flow controllers were calibrated in situ using a constant volume technique. Flow measurement uncertainty was estimated at $1 \%$. Facility pressures were measured using uncorrected ionization gauges calibrated on air at pressures below $0.13 \mathrm{~Pa}$ and capacitance manometers at higher pressures. Temperature measurements were acquired with a two-color pyrometer with a range of $1700-3500^{\circ} \mathrm{C}$ through a quartz window.

The Hall effect current probes were calibrated prior to each test using a dc power supply and a calibrated shunt. Two digital oscilloscopes with four channels each were used to monitor current at each segment and operating voltage. All channels were triggered simultaneously using an external trigger source.

\section{Experimental Procedure}

The arcjet and segmented anode assembly was configured and aligned prior to each test. The alignment of the segments and insulators was verified optically using a boroscope. The 
cathode used had previously been burned in for several hours. This cathode was used to avoid changes in arcjet operation associated with the burn-in of a new cathode. The arcjet was run on hydrogen in all cases. Initial testing was carried out with all segments conducting. Various flow rates and current levels were used to determine the effect that these parameters had on the voltagecurrent characteristic of the arc. Next, the effect of switching individual segments off, so that they were isolated, was investigated. For all starts, all segments were conducting. Then segments were switched off in a sequential order from one to five. This process was continued until the arc extinguished. The current to each segment was monitored on the strip chart recorder. Finally, the set of segments with the pressure taps was installed into the segmented anode assembly. Various flow rates and current levels were used to determine the effect of these parameters on the nozzle pressures. Finally, the background pressure of the vacuum facility was changed using the diffusion pumps.

The minimum current level was controlled by the open circuit voltage level of the PPU. In most cases, a higher current was needed to start the arcjet, and once started, the current was decreased to the desired level. The upper current level was controlled by the heat load to the segments. This factor limited both the maximum current level obtainable and the minimum flow rate. Due to the heat transfer characteristics of the segments, thermal equilibrium was quickly attained after starting; therefore, only short duration tests were needed. As noted in Reference 13, the data obtained from these short operating intervals are representative of data obtained during longer duration runs. At the lower current levels, the maximum propellant flow rate was limited by the voltage the PPU could sustain. At higher current levels, the maximum propellant flow rate was limited by the pumping capacity of the facility.

\section{Results and Discussion}

Arc restrike occurs when operating conditions are such that the arc anode attachment does not remain in a stable position. Wutzke, et al.18,19 have given a description of the physics that govern this arc instability. The anode root, or anode jet, which exists between the plasma column and the position where anode attachment takes place is acted upon by two opposing forces. The fringe gas flow, or the gas flowing between the arc column and the anode wall, imposes a gasdynamic drag force on the anode root which tends to push the root downstream. At the same time there exists an electromagnetic body force (Lorentz force) which pulls the arc root back toward the cathode. If these two forces balance each other, there is a stable anode attachment point, and the anode root does not move. However, if the drag force is greater than the Lorentz force the anode attachment point will move downstream. As the anode root moves downstream and the arc geometry changes, a point will be reached where the arc restrikes upstream of the present root position. The old anode column then dies out, and the arc takes on the preferred, lower resistance path. The maximum distance downstream that the arc travels is proportional to the fringe flow velocity, the arc gap, and the fringe gas density.

Previous researchers have found that this restrike phenomenon occured with hydrogen and nitrogen, but not with helium or argon. 20 It was suggested that the disassociation energy of the propellant may be important in determining how difficult it was for the arc anode attachment point to remain in a single position and to breakdown the cooler gas approaching it. Another important difference is the thermal conductivity of the propellant. Hydrogen and nitrogen have higher thermal conductivities which lead to a more constricted arc due to the ready loss of heat to the gas surrounding the arc column. When the arc is more constricted the anode root is longer, and the gasdynamic drag force acts over a larger area; therefore, the anode attachment point is more readily pushed downstream, and the likelihood of restrike phenomenon occuring is increased.

The initial tests showed that the arc voltage instabilities were caused by a restriking phenomenon. The arc restrike had a frequency in the range of $75-200 \mathrm{kHz}$. Figure 5 shows oscilloscope traces for the arc voltage and the segment currents for a flow rate of $20 \mathrm{mg} / \mathrm{s}$ and a current of $15 \mathrm{~A}$. The voltage rose from $70 \mathrm{~V}$ to $135 \mathrm{~V}$ and then abruptly fell back to its minimum value at a frequency of $75 \mathrm{kHz}$. This voltage oscillation was caused by the restriking of the arc. The movement of the arc is illustrated in Figure $5 \mathrm{~b}$ which shows the current through the different segments of the anode. For these flow conditions, the arc was confined primarily to the first two segments. From the figure it can be seen that for a typical restrike cycle, the arc moves downstream and the current to segment one decreases, concurrently the current to segment two increases. This corresponds to a voltage increase. The arc attachment continues 
to move downstream until the voltage has reached its maximum value; at this point the arc restrikes to an average initial position, and the cycle starts over.

As stated by Sankovic and Berns 13 , the arc restrike was current and flow rate dependent. For a given current, there is a flow rate above which the arcjet voltage remains in constant restrike mode. As the flow rate is increased above this point, the distance that the arc travels downstream increases, and the maximum arc voltage increases. The minimum voltage tends to remain relatively constant, implying the arc restrikes back upstream to an average position. Figure 6 shows the change in segment current distribution as the flow rate is increased. The arcjet was started at $20 \mathrm{mg} / \mathrm{s}$ and $15 \mathrm{~A}$, corresponding to the left side of the figure. Keeping the current constant, the flow rate was then gradually increased to $38.5 \mathrm{mg} / \mathrm{s}$, at which point the arc was extinguished. At $20 \mathrm{mg} / \mathrm{s}$, current was only present in segments one and two. As the flow rate was increased, the current to segments one and two decreased, while the current in segment 3 increased. Eventually, a small amount of current was noted in segments four and five. The "noisiness" of the current signals corresponds to arc restrike, as measured by the strip chart recorder.

The arc attachment point was almost always fully contained in the subsonic portion of the nozzle. Only at very high flow rates was there any noticeable current to segments four or five. As seen from Figure 2, segments 1,2,3, and a small portion of segment 4 make up the subsonic flow regime of the nozzle (upstream of the throat). For most flow and current settings, nearly all of the current was seen to flow to segments one and two. To still maintain a subsonic attachment but reduce energy lost to the walls, the subsonic region of the nozzle was shortened. This was accomplished by removing segment 2 and one of the boron nitride insulators. Figure 7 shows the arc voltage and segment current for the anode configuration with segment 2 removed. As in Figure 5, the flow rate was $20 \mathrm{mg} / \mathrm{s}$ and the current was $15 \mathrm{~A}$. Figure $7 b$ shows that the current was primarily to segments 1 and 3 with a small amount of current being carried by segment 4 . This is different from the situation in Figure $5 b$ where the current, thus the arc attachment, was confined to segments 1 and 2. Once again, in a particular restrike cycle, as the voltage increases the current distribution is transferred from segment 1 to segment 3 with some current to segment 4 . The downstream current movement is indicative of the downstream movement of the arc attachment. Again, as in Figure 5a, the voltage restrike occurs at a frequency of $75 \mathrm{kHz}$, the minimum voltage is approximately $70 \mathrm{~V}$, and the maximum voltage is approximately $135 \mathrm{~V}$. The similar voltage values obtained with and without segment 2 included implies that the length of the arc was the same in both cases. However, the reduction in length of the subsonic portion of the nozzle drove the arc attachment closer to the nozzle throat in segment 4.

A comparison of Figures $8 \mathrm{a}$ and $8 \mathrm{~b}$ also illustrates the effect of removing segment 2 . Both sets of current traces are for a flow rate of $30 \mathrm{mg} / \mathrm{s}$ and a current of $15 \mathrm{~A}$. In Figure $8 \mathrm{a}$ all segments were included in the anode/nozzle. The current was carried by segments 1,2 , and 3 . No current was seen in either segment 4 or 5 . In Figure $8 \mathrm{~b}$, segment 2 was taken out. For this case the current was mainly carried by segments 1 and 3 but there was a noticeable amount of current carried by segment 4 (the segment containing the nozzle throat). Therefore, the reduction in length of the subsonic region of the nozzle caused the arc attachment to reach a position much closer to the throat.

The ability to force the arc to attach on particular segments was also studied. The electrical arrangement shown in Figure 3 was used. As previously mentioned, the arcjet was started with all segments conducting. After ignition, segments were switched off sequentially until the arc was extinguished. Stabilization time was allowed between each switch operation. It was found that the arc would not ignite unless segment 1 was conducting. With segment 1 switched off, the electrode gap was increased. Breakdown of this elongated electrode gap could not be achieved with the starting circuit used.

The effects on the segment current due to switching the segments is illustrated in Figure 9. For Figures $9 \mathrm{a}, 9 \mathrm{~b}$, and $9 \mathrm{c}$ the flow rate was 10 $\mathrm{mg} / \mathrm{s}$ and the current was $15 \mathrm{~A}$. In $9 \mathrm{a}$, all of the arc current was carried by segment 1 after ignition. The arcjet was initially in restrike mode but then transitioned to a stable voltage mode after a few seconds. When segment 1 was switched off, the arc attachment was driven to segment 2 with no current carried by segments 3 , 4 , or 5 . The arcjet continued to operate in a stable regime. Switching segment 2 off forced the arc current to segment 3. Finally, when segment 3 was switched off, the arc extinguished. In Figure 9b, where segment 2 was removed, the 
arc attachment exhibited similar behavior. However, for this case, when segment 3 was switched off, the arc current was carried by segments 4 and 5 with segment 4 carrying most of the current. At this point there was about one second of large scale voltage instability followed by a stable mode. For segment 5 to carry current, the arc attachment had to be downstream of the nozzle throat in segment 4. Therefore, through the switching sequence, the anode attachment was moved step by step down the subsonic region until some of the current attached in the supersonic region of the nozzle. Finally, when segment 4 was switched off, the arc extinguished. The arcjet started and remained in a restrike mode for the case shown in Figure 9c. Initial operation with all segments conducting shows that the anode attachment was restriking across segments 1 and 2 . After switching segment 1 off, the attachment was moved to a position across both segments 2 and 3. When segment 2 was switched off the arc extinguished. In other cases, such as Figure 9d, the arcjet could be transitioned from an initial restrike mode to a stable mode by switching off the first segment.

An attempt was made to analyze the pressure drop across the nozzle throat for various operating conditions. As mentioned previously, two pressure taps were positioned in the nozzle. One in segment 3 at $0.26 \mathrm{~cm}$ upstream of the throat and one in segment 4 at $0.083 \mathrm{~cm}$ downstream of the throat. The pressure values recorded are listed in Table I. From Table I it can be seen that the upstream and downstream pressures increased with increasing flow rate and increasing current. Increasing the flow rate caused an increase in the feed pressure, this in turn increased the pressure on both sides of the throat. Also, increasing the current level increased the power input to the gas which caused the gas temperature to increase, which in turn caused the pressure to rise.

The internal pressures also changed when the facility background pressure was changed. The change in facility pressure was accomplished by switching from mechanical roughing vacuum pumps to diffusion pumps. The flow rate of gas through the arcjet was $10 \mathrm{mg} / \mathrm{s}$. Using the roughing pumps, a background pressure of 18.0 $\mathrm{Pa}$ was reached. With the diffusion pumps in operation, the background pressure was reduced to $0.05 \mathrm{~Pa}$. Two current levels, $2 \mathrm{~A}$ and $3 \mathrm{~A}$, are shown in Table I that compare the effect of the background pressure. Low currents were used so that the segments would not become excessively hot. In both cases, when the background pressure was reduced, the upstream pressure increased while the downstream pressure remained the same. Figures $10 \mathrm{a}$ and $10 \mathrm{~b}$ show the segment currents and pressure values obtained for both the high and low facility pressure cases. In both cases, the anode attachment remained in the subsonic regime for varying flow rates and currents. From Laval nozzle flow theory, a change in background pressure should not affect the upstream pressure. This is the case when there is a subsonic to sonic transition at the throat, as with this nozzle. Due to the large pressure ratio of the exit pressure to the background pressure for either of the background settings, the downstream pressure should have also been unaffected by the change made in the facility pressure. The pressure adjustment of the exiting flow should occur only in oblique shock waves outside of the nozzle exit. Therefore, some other effect on the flow caused the upstream pressure to increase. Because of the high viscosity of the flow, the subsonic boundary layer should be significant. It is possible for disturbances to propagate upstream via the boundary layer; however, that does not explain the phenomenon noted here. In this case the downstream pressure is essentially unaffected by changing the facility background pressure from $18 \mathrm{~Pa}$ to $0.05 \mathrm{~Pa}$, while the pressure in the arc chamber changed by over $30 \%$.

As mentioned in Reference 13, the arcjet voltage characteristic also changed when the facility pressure was reduced. At flow rate and current levels where restrike was the mode of operation at the higher facility pressures, the arc would restrike after ignition but would then transition to a much lower frequency voltage instability at lower background pressures. The voltage transitioned between a lower level and a voltage that was typically 20 volts higher. The arc voltage would remain at the lower value for several seconds then jump to a higher value and remain there for several seconds before returning to the lower level. There were also brief transitions to restrike, but they only occurred for a short duration, usually after the arc jumped back to the lower voltage. This cycle was repeated continuously while the arcjet was in operation but the amount of time that the voltage remained at a fixed value was sporadic.

A possible explanation for this voltage characteristic and the upstream pressure increase at lower background pressure is thermal choking. The arc would start to restrike but would then become "stuck" at its maximum length for 
several seconds and then would jump back to its minimum value and repeat the cycle. When the arc attachment is pushed downstream by the drag force of the flow and reaches its greatest length, it causes a thermal block near the throat. The temperature in the arc is much higher than the surrounding gas, therefore the density of the plasma is lower than the surrounding flow. This lower density plasma causes the upstream velocity to increase in order to maintain the constant mass flow through the nozzle. For the velocity to increase, the upstream pressure has to increase. If the velocity is high enough, the drag force will increase enough to overcome the magnetic body force and push the arc farther downstream. It remains stable in this position for a length of time until the drag force is no longer strong enough to overcome the magnetic body force on the arc and restrike occurs. This process can then recycle. Further research is needed to fully characterize the pressure distribution through the nozzle. Using only two pressure taps provided an initial view of the flow dependence, but to fully explain the phenomena occuring more data need to be obtained.

Possibly, the reason why this thermal choking takes place in the lower facility pressure and not in the higher facility pressure is the decrease in heat transfer to the surroundings. In a lower pressure environment, the ability of the nozzle to transfer heat to its surroundings decreases because of the decreased density of species in the gas surrounding the outside of the nozzle. This decrease in outward heat transfer causes the nozzle temperature to increase. The temperature increase will affect the gas flow and the geometry of the arc. This may be the initial reason for the thermal choking to take place. Once the effect occurs, the pressure increase produces higher arc voltages by "pinning" the anode attachment farther downstream of the cathode. This increased voltage leads to greater power input to the gas which enhances the thermal choking effect further by raising the gas temperature and pressure.

\section{Concluding Remarks}

A subsonic-arc-attachment thruster with a segmented anode was operated at various conditions on hydrogen. A high frequency voltage instability was identified and shown to be caused by arc restrike. This restrike occurred at frequencies between 75 and $200 \mathrm{kHz}$. The restrike cycle was shown to consist of an initial arc gap breakdown followed by an elongation of the arc due to a downstream movement of the anode attachment point, and finally an arc restrike back to an initial upstream point. The movement of the arc root during restrike was quantified by obtaining data for arc current contribution to the individual segments of a segmented anode.

For all operating conditions where restrike occured, the anode attachment remained in the subsonic region of the nozzle. Variations in flow rate and current settings had an effect on the behavior of the voltage instability. Shortening the subsonic portion of the anode caused the arc attachment point to seat closer to the throat region of the nozzle. Theoretically this should have improved performance by decreasing plasma losses to the nozzle wall before expansion could occur downstream of the throat. However, satisfactory thrust data for this comparison could not be obtained due to the complexity of the added cabling associated with segmented-anode operation.

The ability to control the position of arc attachment by electrical switching of the anode segments was illustrated. Forcing the arc out of restrike was achieved along with stepping the arc root from the subsonic region to the supersonic region of the anode. Finally, the restrike phenomenon was shown to be affected by facility background pressure. The idea presented here is that the flow is not directly affected but the heat transfer from the anode to the surrounding background gas is decreased with decreasing background pressure. This decrease in heat transfer away from the gas flow passing through the nozzle will affect the flow properties and thus affect the voltage stability.

\section{References}

1. John, R.R., "Thirty-Kilowatt Plasmajet Rocket Engine Development," Summary Report on the Second Year Development Program, Avco Corp., RAD-TR-64-6, (also NASA CR54044), July 1964.

2. Todd, J.P. and Sheets, R.E., "Development of a Regeneratively Cooled 30-kW Arcjet Engine," AIAA Journal, Vol. 3, No. 1, pp. 122-126, 1965.

3. Sankovic, et al., "Hydrogen Arcjet Technology," IEPC 91-018, Proceedings of the 22nd International 
Electric Propulsion Conference, (also NASA TM105340), October 1991.

4. McCaughey, OJ., et al., "Research and Advanced Development of a $2 \mathrm{~kW}$ ArcJet Thrustor," Summary Report, Plasmadyne Corp., NASA CR-54035, June 1964.

5. Curran, F.M. and Haag, T.W., "Extended Life and Performance Test of a Low-Power Arcjet," Journal of Spacecraft and Rockets, Vol. 29, No. 4, pp. 444-452, July 1992.

6. Smith, W.W., et al., "Low Power Hydrazine Arcjet Flight Qualification," IEPC-91-148, Proceedings of the 22nd International Electric Propulsion Conference, October 1991.

7. Sanks, T.M., et al., "The Status and Future. Plans for Electric Propulsion Development by the United States Air Force," IEPC-91-006, Proceedings of the 22nd International Electric Propulsion Conference, October 1991.

8. Polk, J.E. and Goodfellow, K.D., "Endurance Test of an Ammonia Arcjet at $10 \mathrm{kWe}, "$ IEPC-91-068, Proceedings of the 22nd International Electric Propulsion Conference, October 1991.

9. Hamley, J.A., et al., "10 kW Power Electronics for Hydrogen Arcjets," Proceedings of the 1992 JANNAF Propulsion Conference, (also NASA TM105614), February 1992.

10. Haag, T.W. and Curran, F.M., "HighPower Hydrogen Arcjet Performance," AIAA 91-2226, (also NASA TM105143), June 1991.

11. "H2 Arcjet Performance Mapping Program," Rocket Research Co. Report 92-R-1615 (also NASA CR-191073), January 1992.

12. Haag, T.W., "Recent Testing of 30-kW Hydrogen Arcjet Thrusters," AIAA 931902, June 1993.

13. Sankovic, J.M. and Berns, D.H., "Performance of a Low-Power Subsonic-Arc-Attachment Arcjet Thruster," AIAA 93-1898, June 1993.
14. Curran, F.M. and Haag, T.W., "Arcjet Component Conditions Through a Multistart Test," AIAA 87-1060, (also NASA TM89857), May 1987.

15. Curran, F.M., et al., "Performance Characterization of a Segmented Anode Arcjet Thruster," AIAA 90-2582, (also NASA TM 103227), July 1990.

16. Gruber, R.P., Gott, R.W., and Haag, T.W., "5-kW Arcjet Power Electronics," AIAA 89-2725, (also NASA TM102108), July 1989.

17. Morren, W.E. and Lichon, P.J., "Low Power Arcjet Test Facility Impacts," AIAA 92-3532, (also NASA TM105876), July 1992.

18. Wutzke, S.A., Pfender, E., and Eckert E.R.G., "Symptomatic Behavior of an Electric Arc with a Superimposed Flow," AIAA Journal, Vol.6, No. 8, pp 1474-1482, 1968.

19. Wutzke, S.A. and Pfender, E., "Electrical Breakdown and Anode Heat Transfer in a DC Arc with Superimposed Axial Flow," Progress in Heat and Mass Transfer, Vol.2, pp 427449., 1969.

20. Todd, J.P., et al., "Development of a Thermal Arc Engine," ASD-TDR-62749, July 1962. 
Table I.- Pressures upstream and downstream of the nozzle throat for various operating conditions.

\begin{tabular}{|c|c|c|c|c|}
\hline $\begin{array}{c}\text { Flow Rate } \\
(\mathrm{mg} / \mathrm{s})\end{array}$ & $\begin{array}{c}\text { Current } \\
\text { (Amps) }\end{array}$ & $\begin{array}{c}\text { Tank Pressure } \\
(\mathrm{Pa})\end{array}$ & $\begin{array}{c}\text { Pressure } \\
\text { Upstream of } \\
\text { Throat }(\mathrm{kPa})\end{array}$ & $\begin{array}{c}\text { Pressure } \\
\text { Downstream of } \\
\text { Throat }(\mathrm{kPa})\end{array}$ \\
\hline \hline 30 & 0 & 65.9 & 27.2 & 3.33 \\
35 & 0 & 70.7 & 31.8 & 3.98 \\
40 & 0 & 86.0 & 36.7 & 4.67 \\
30 & 6 & 65.9 & 57.8 & 5.79 \\
35 & 6 & 70.7 & 66.9 & 6.72 \\
40 & 6 & 86.0 & 73.1 & 7.56 \\
10 & 3 & 18.0 & 12.1 & 1.67 \\
10 & 3 & 0.05 & 16.3 & 1.66 \\
10 & 2 & 18.0 & 11.7 & 1.60 \\
10 & 2 & 0.05 & 16.1 & 1.60 \\
\hline
\end{tabular}

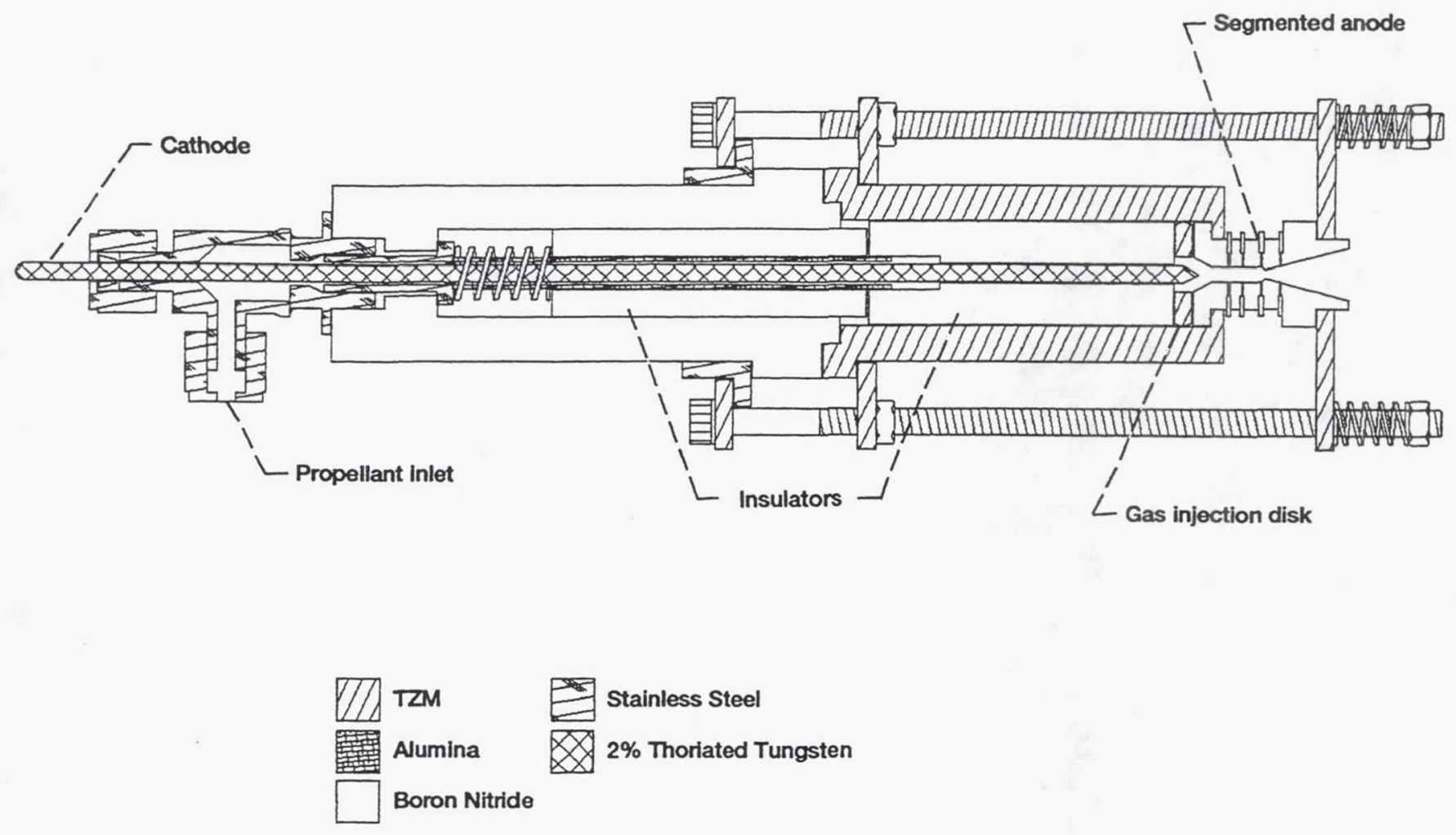

Figure 1.-Segmented-anode arcjet thruster cross sectional schematic. 


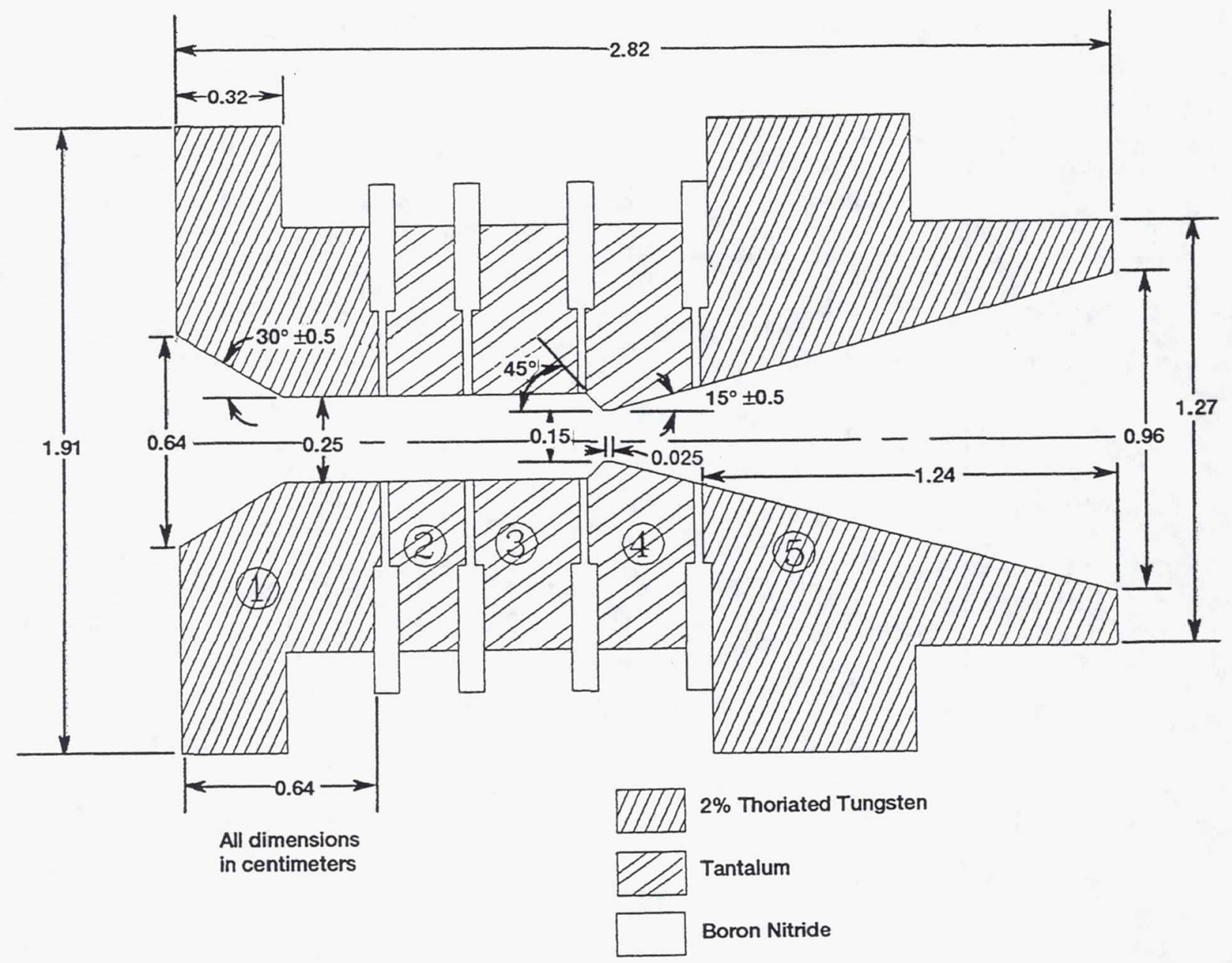

Figure 2.-Segmented anode.

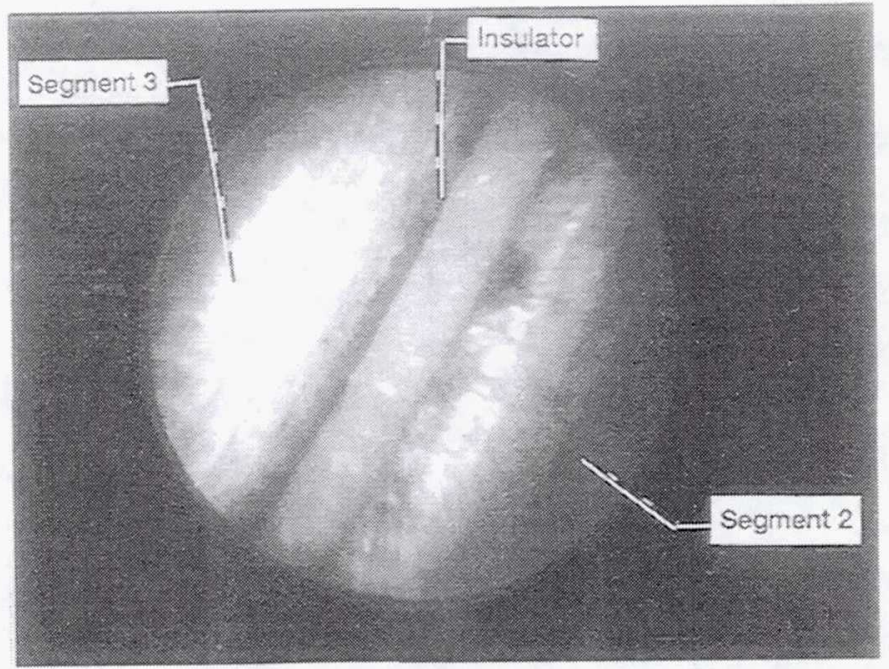

Figure 3.-Boroscope photograph showing typical alignment of segments and insulators. Boron nitride insulator is $0.025 \mathrm{~cm}$ thick. 


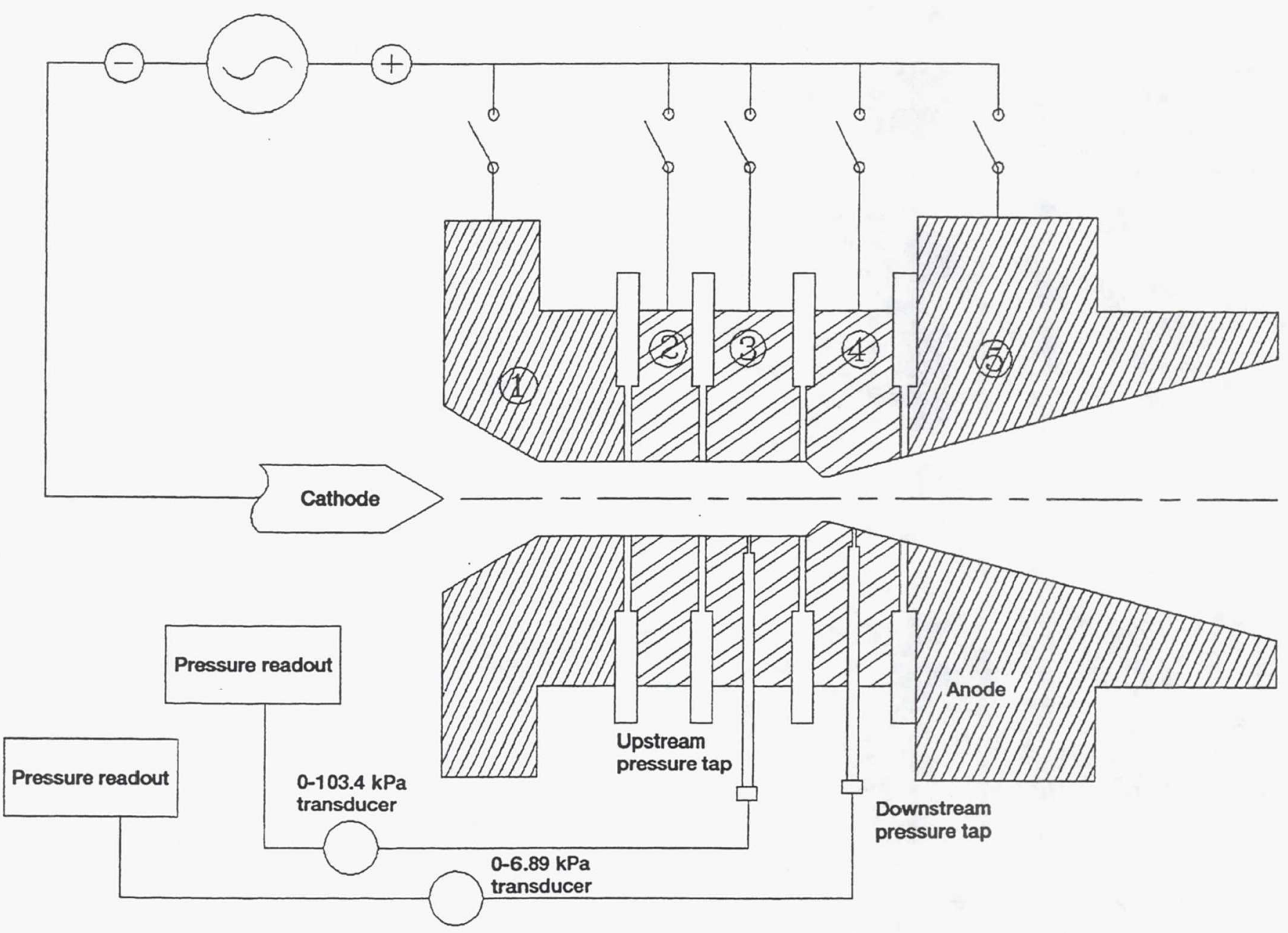

Figure 4.-Simplified diagram of electrical and pressure configurations. 


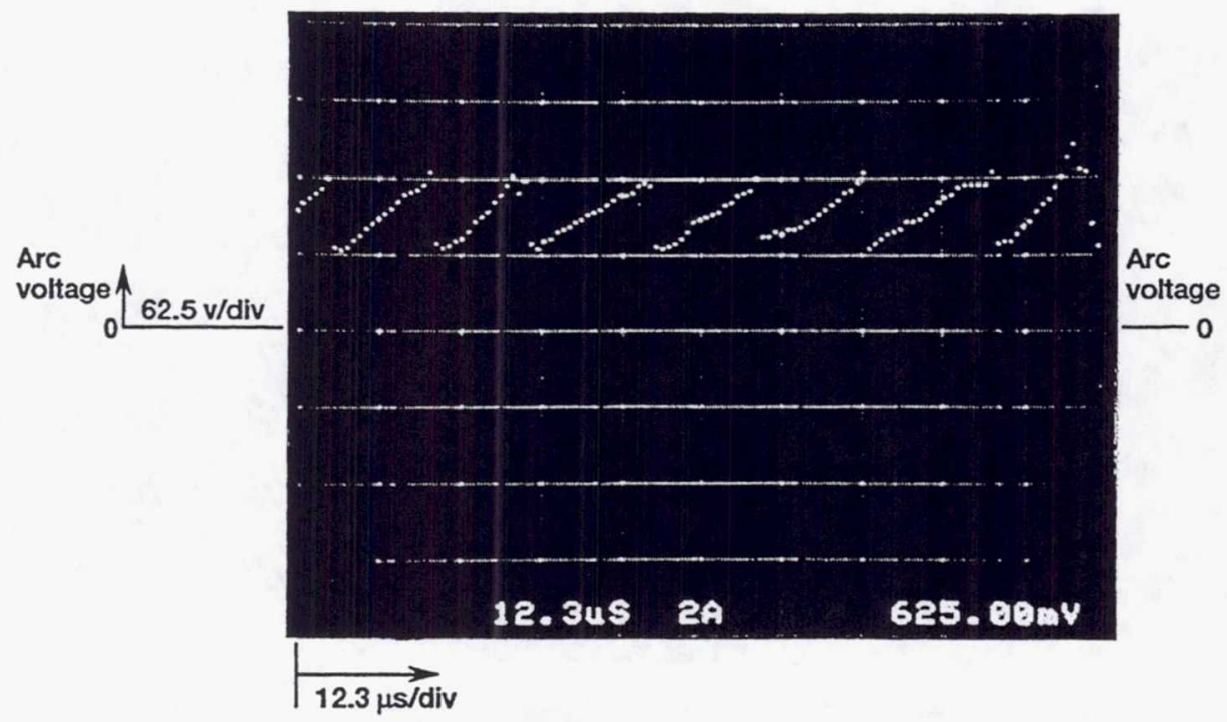

(a) Arcjet voltage; $20 \mathrm{mg} / \mathrm{s}, 15 \mathrm{~A}$.

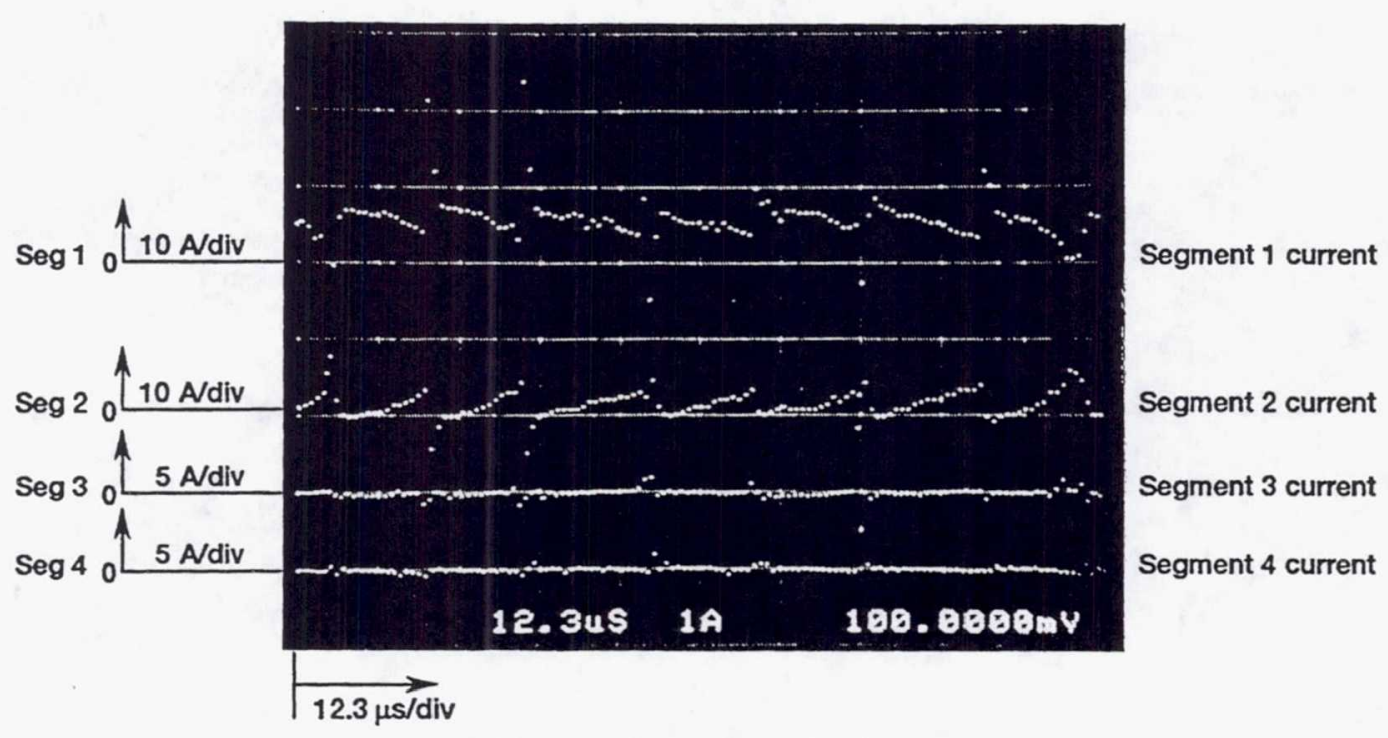

(b) Segments $1-4 ; 20 \mathrm{mg} / \mathrm{s}, 15 \mathrm{~A}$.

Figure 5.-Arcjet voltage and segment currents; all segments included. 

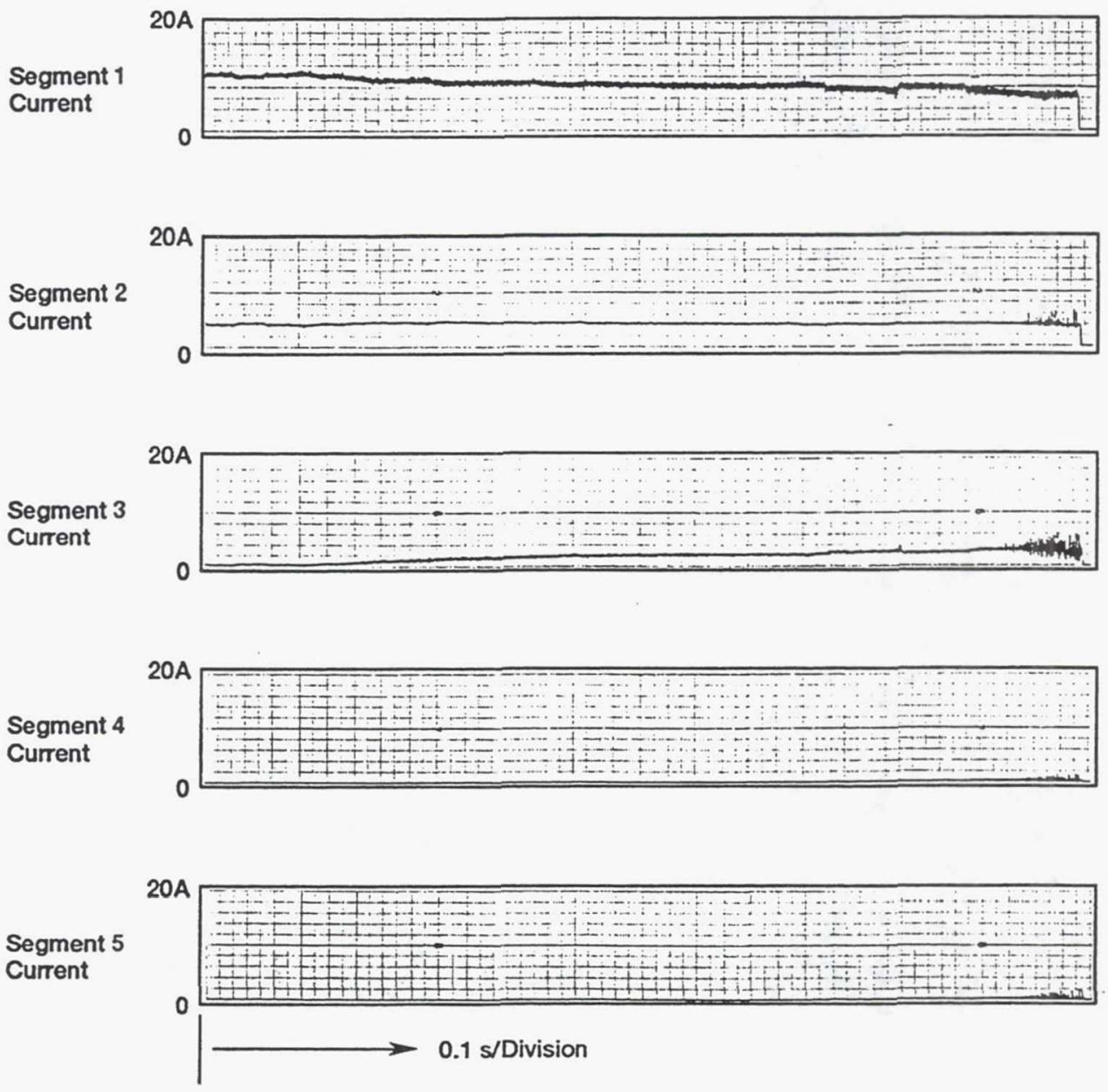

Figure 6.-Strip chart record showing current flow from arc to segments 1-5 at a total discharge current of $15 \mathrm{~A}$ and a propellant flow rate of $20 \mathrm{mg} / \mathrm{s}$ increasing to $39 \mathrm{mg} / \mathrm{s}$. 


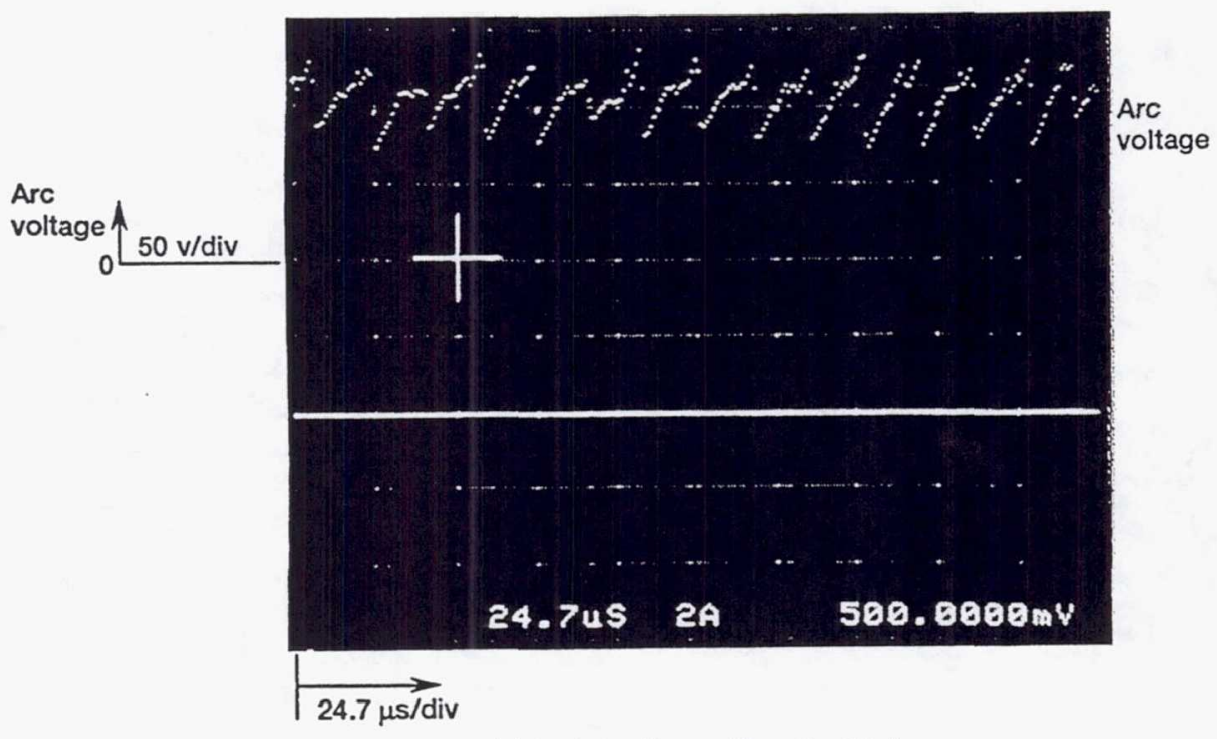

(a) Arcjet voltage; $20 \mathrm{mg} / \mathrm{s}, 15 \mathrm{~A}$.

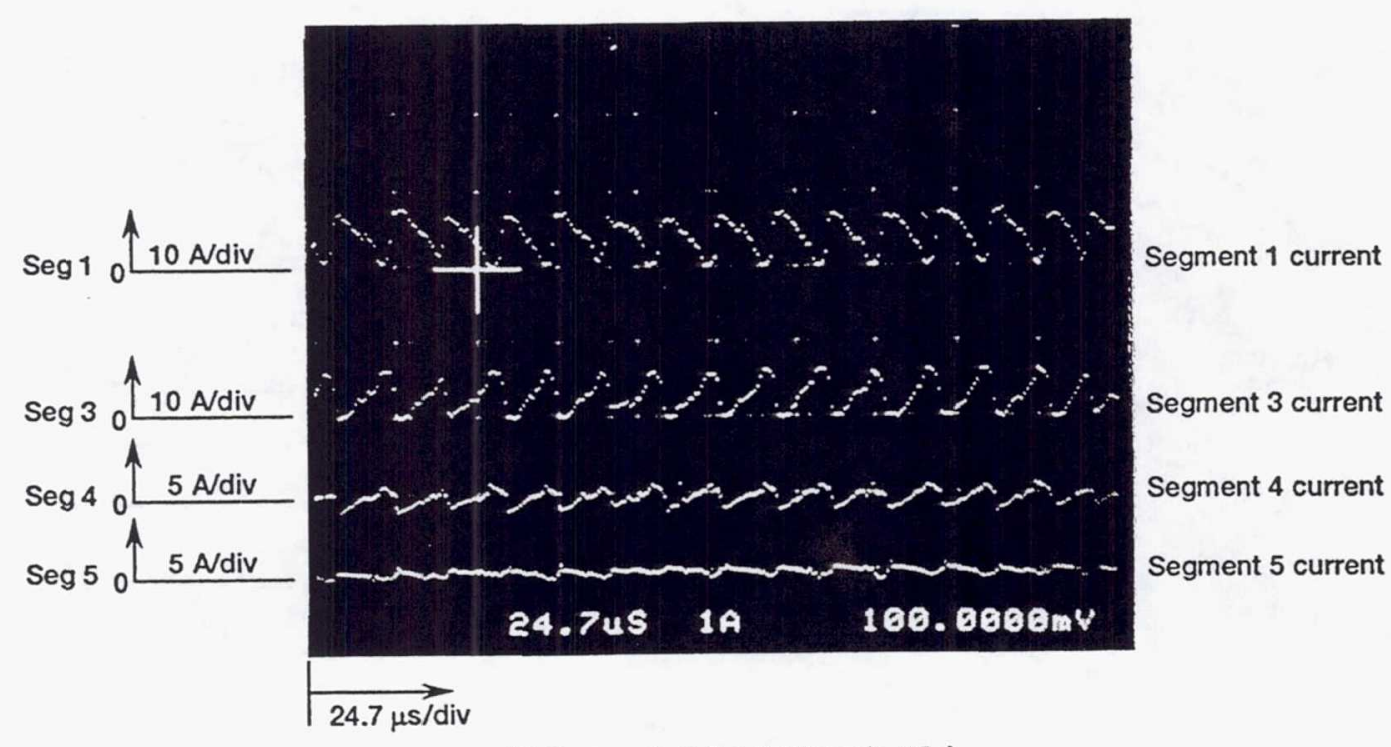

(b) Segments $1,3,4,5 ; 20 \mathrm{mg} / \mathrm{s}, 15 \mathrm{~A}$.

Figure 7.-Arcjet voltage and segment currents; segment 2 removed. 

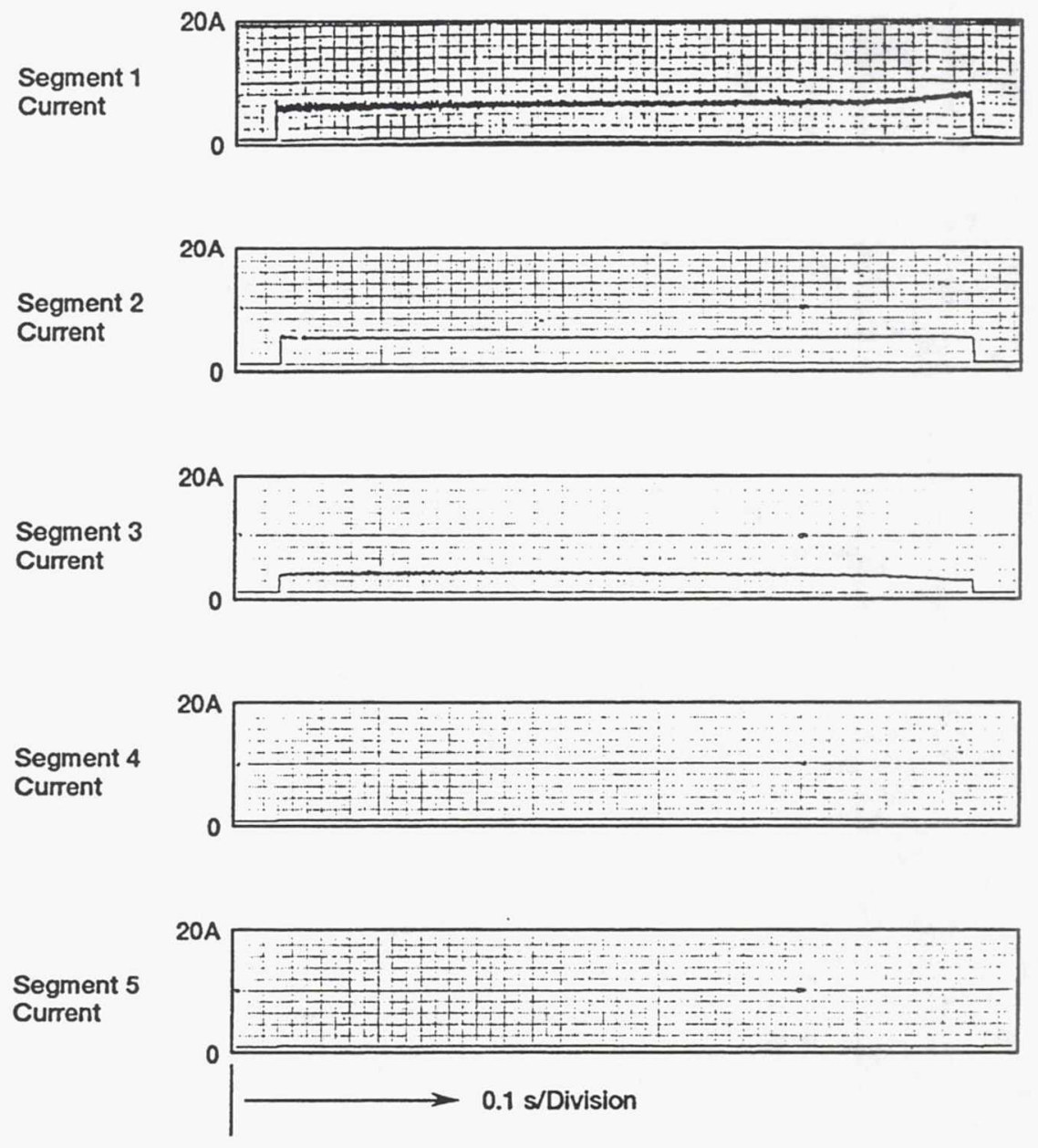

(a) All segments included.

Figure 8.-Strip chart record showing current flow to individual segments at a total discharge current of $15 \mathrm{~A}$ and $30 \mathrm{mg} / \mathrm{s}$ propellant flow rate. 

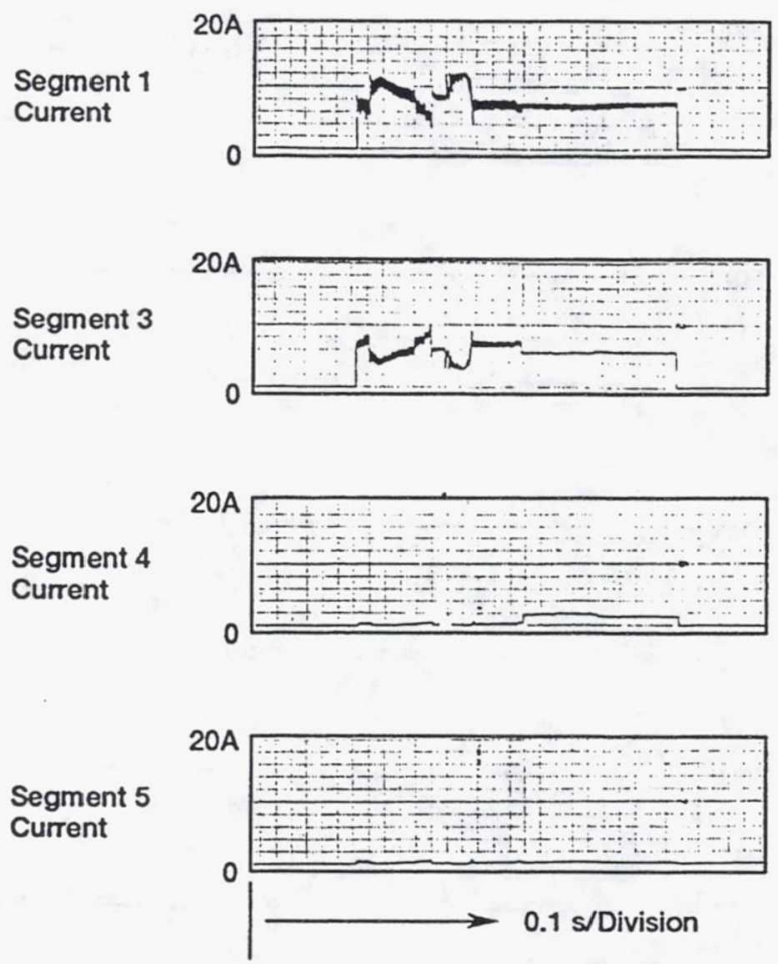

(b) Segment 2 removed.

Figure 8.-Concluded. 

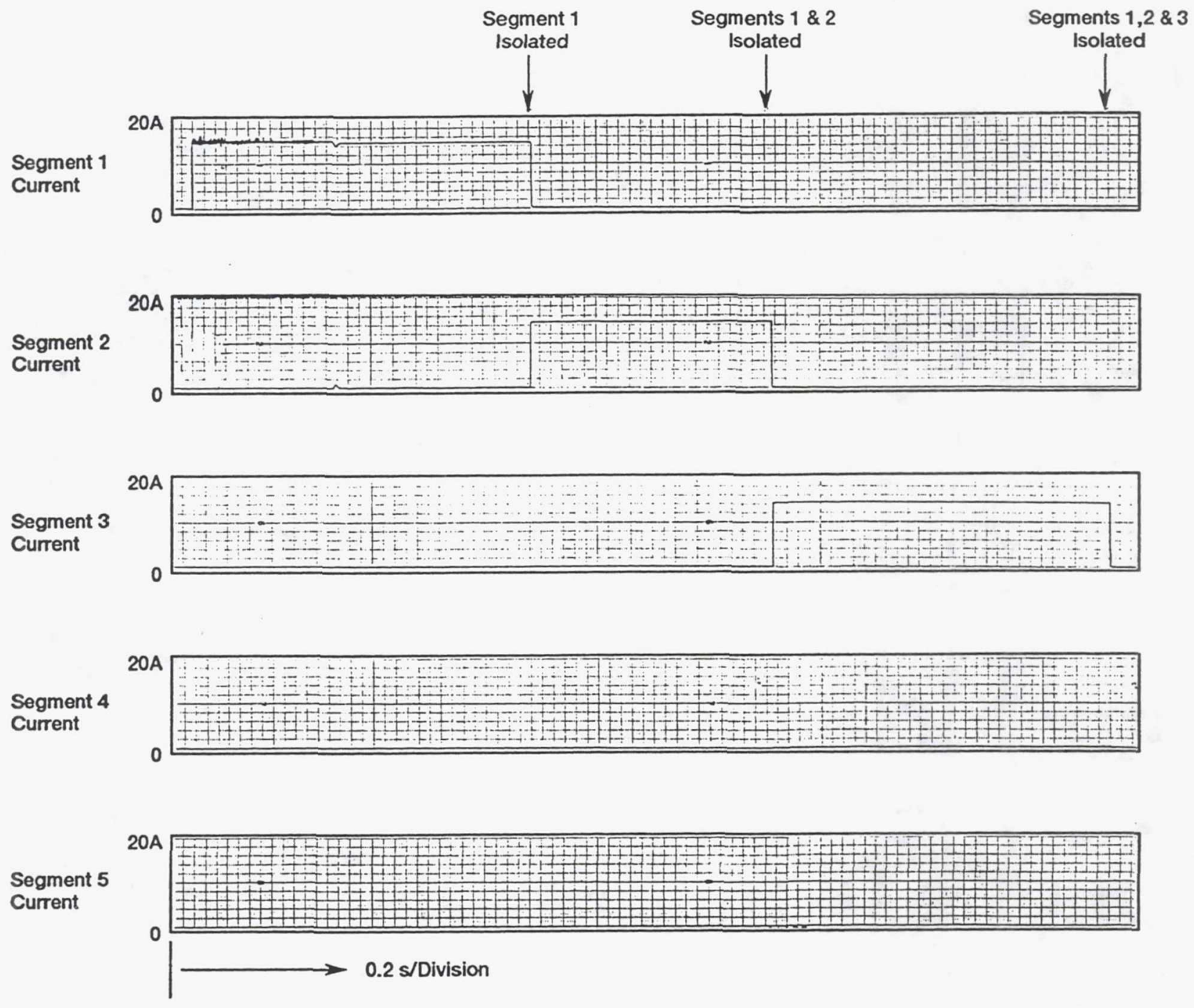

(a) All segments included; $15 \mathrm{~A}$ total discharge current, and $10 \mathrm{mg} / \mathrm{s}$ propellant flow rate.

Figure 9.-Strip chart record showing effect on current distribution when selected segments are isolated. 

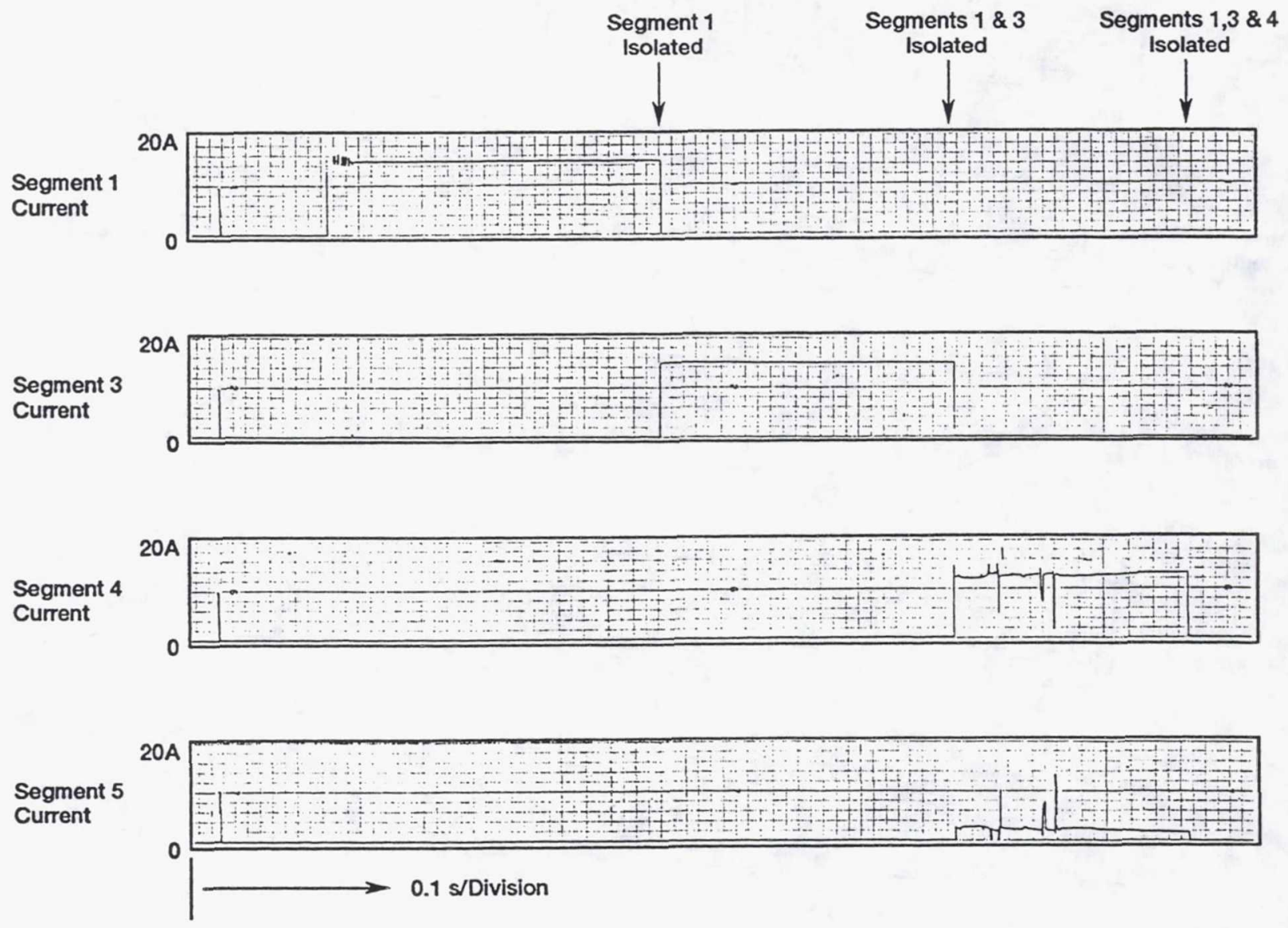

(b) Segment 2 removed; $15 \mathrm{~A}$ total discharge current, and $10 \mathrm{mg} / \mathrm{s}$ propellant flow rate.

Figure 9.-Continued. 

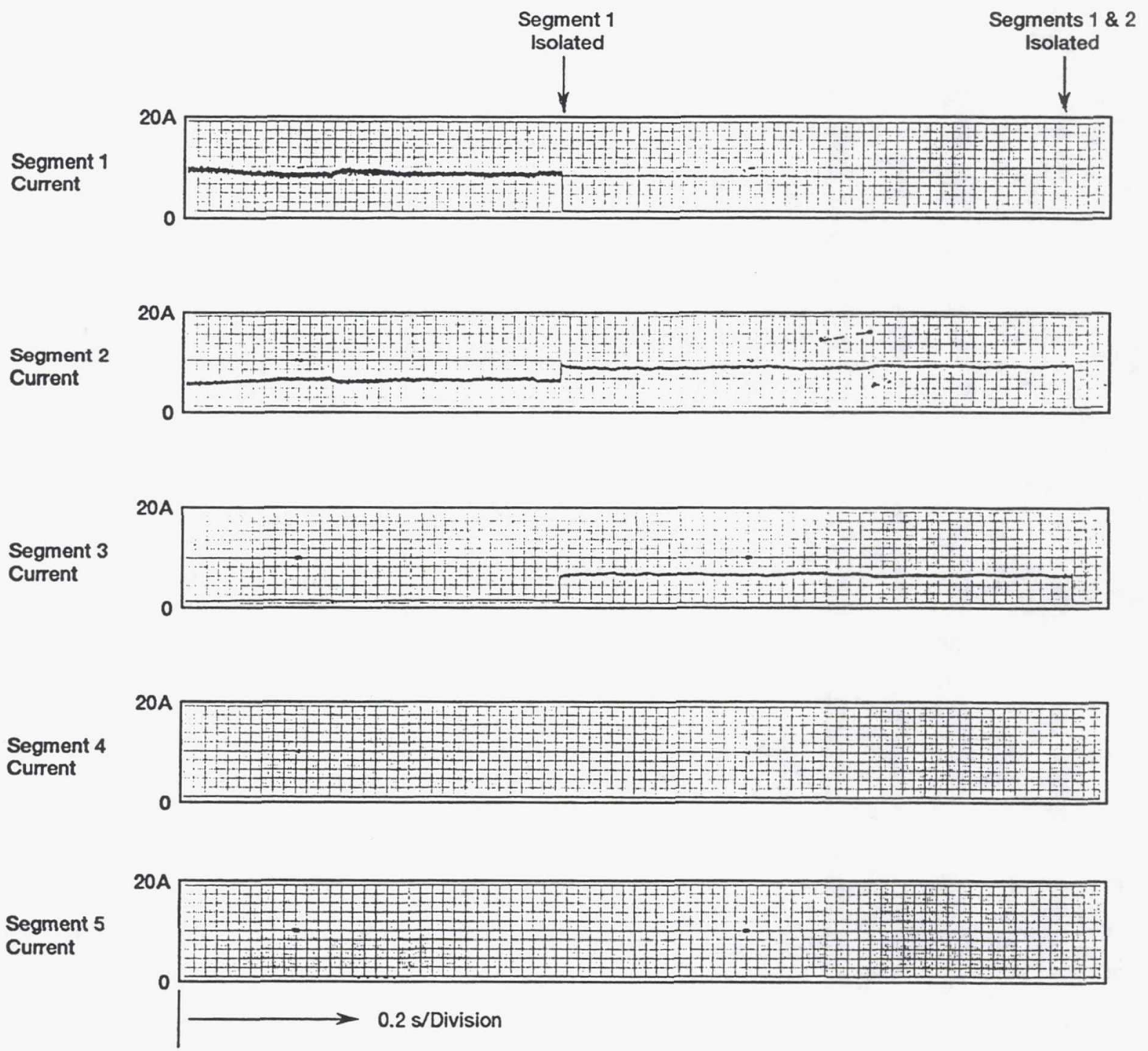

(c) All segments included; $15 \mathrm{~A}$ total discharge current, and $10 \mathrm{mg} / \mathrm{s}$ propellant flow rate.

Figure 9.-Continued. 

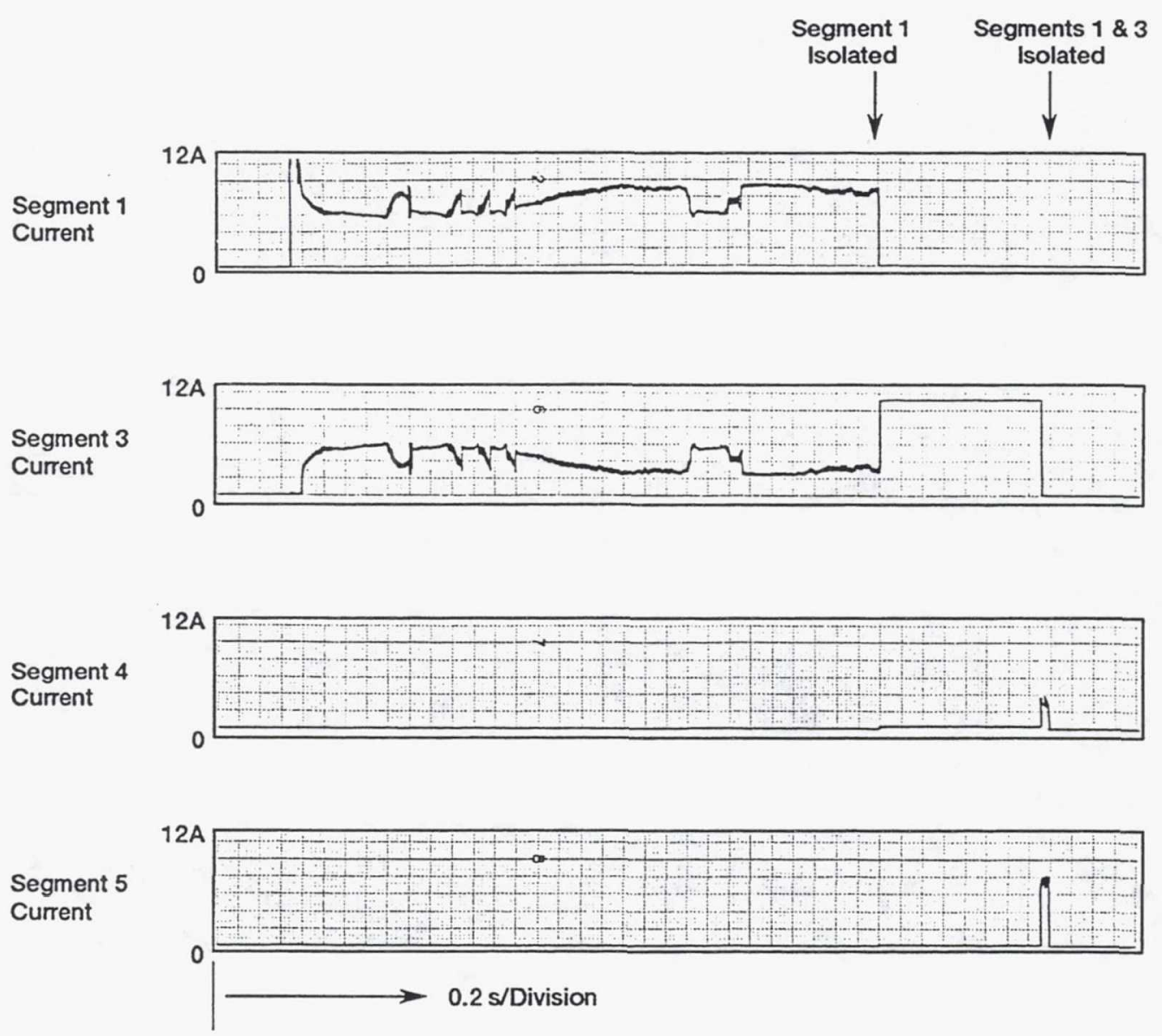

(d) Segment 2 removed; 12 A total discharge current, and $20 \mathrm{mg} / \mathrm{s}$ propellant flow rate.

Figure 9.-Concluded. 

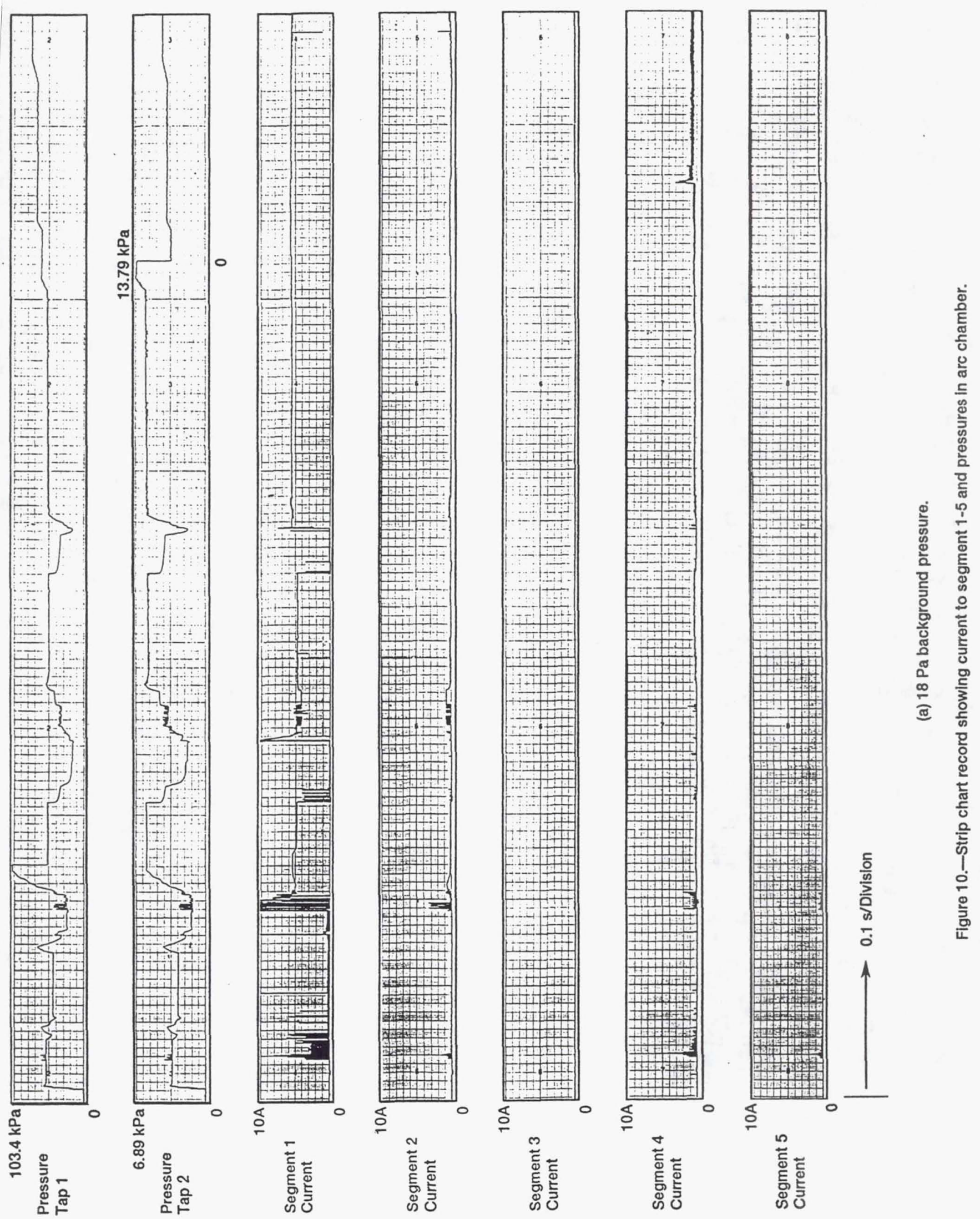

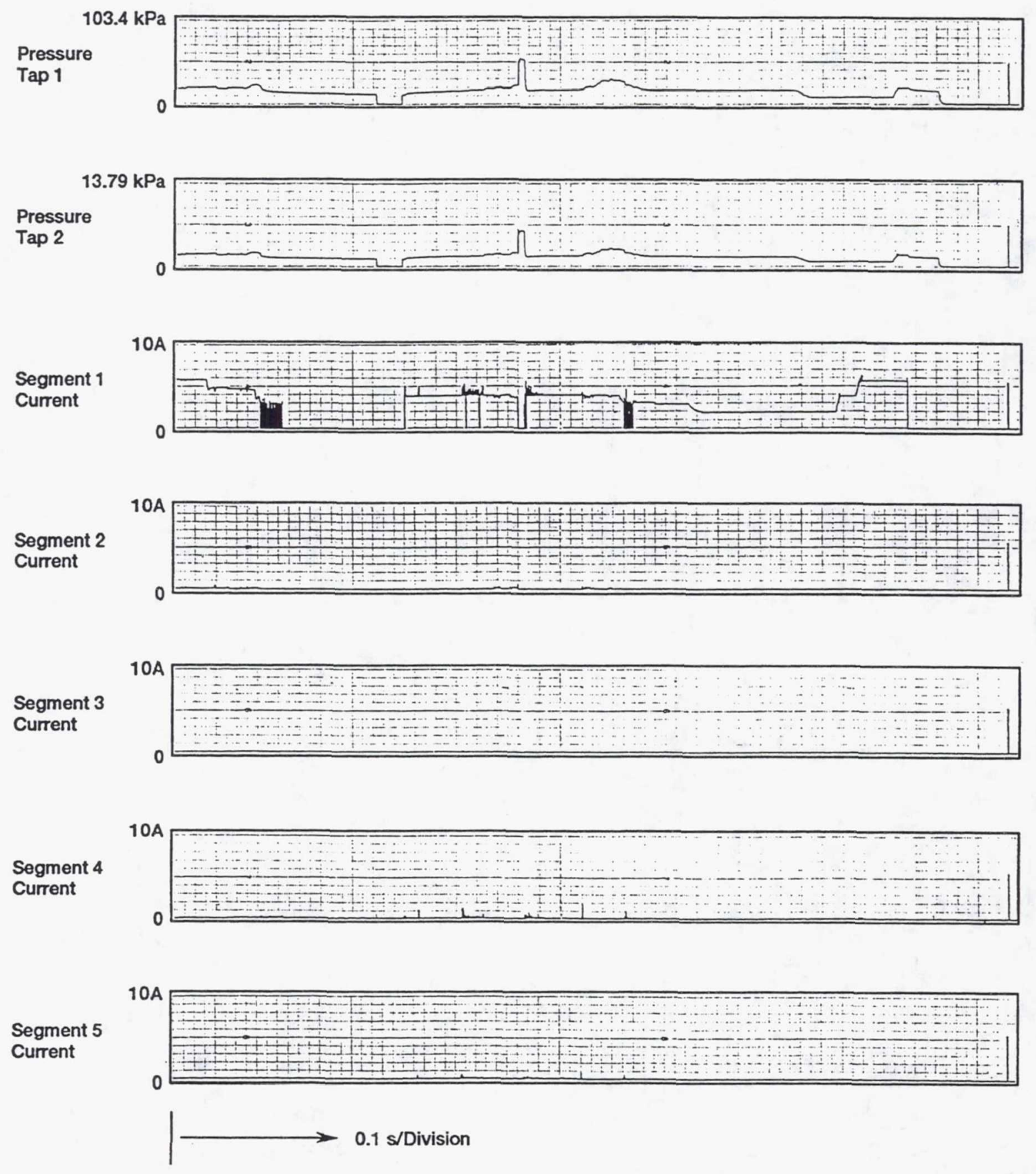

(b) $0.047 \mathrm{~Pa}$ background pressure.

Figure 10.-Concluded. 

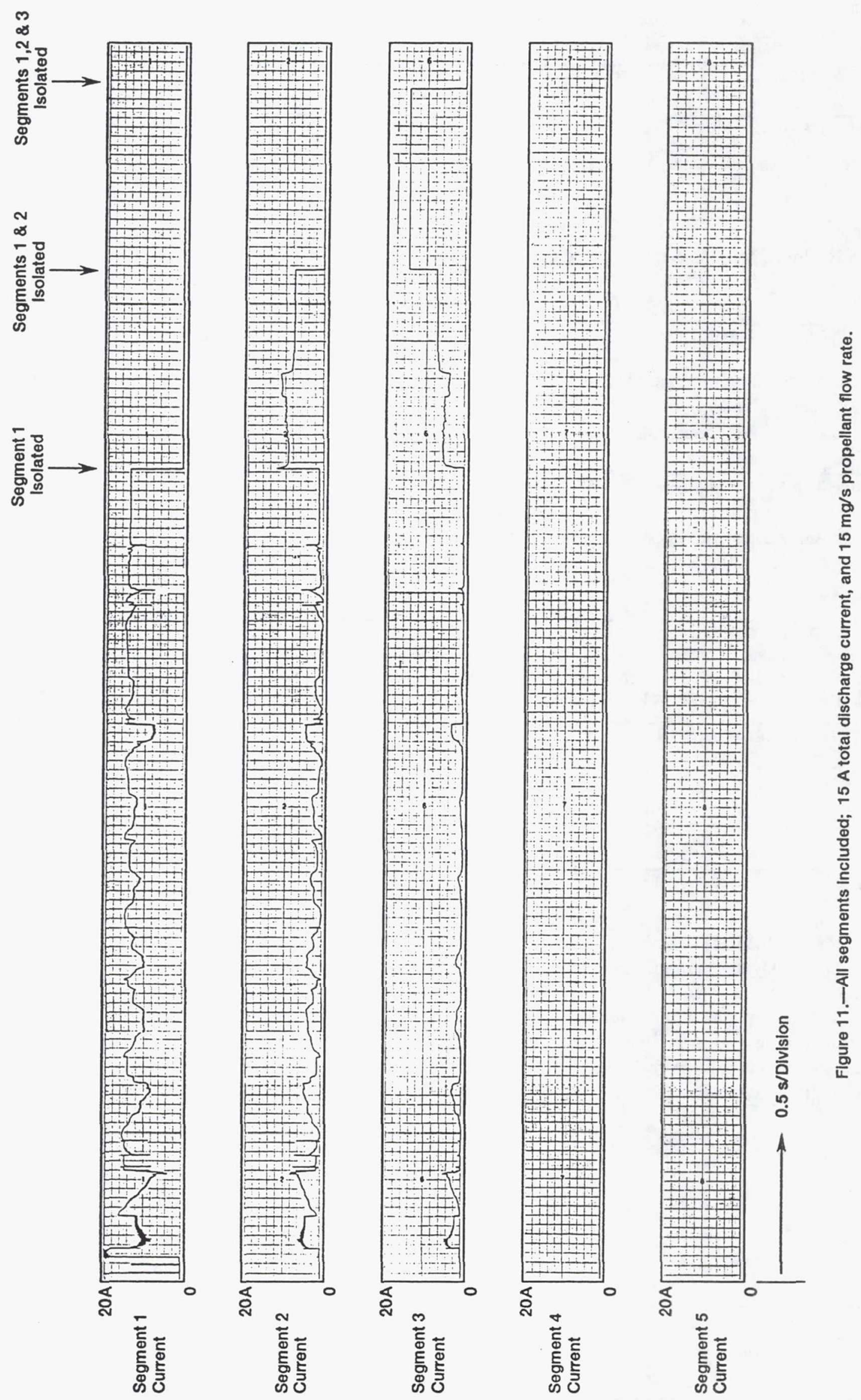


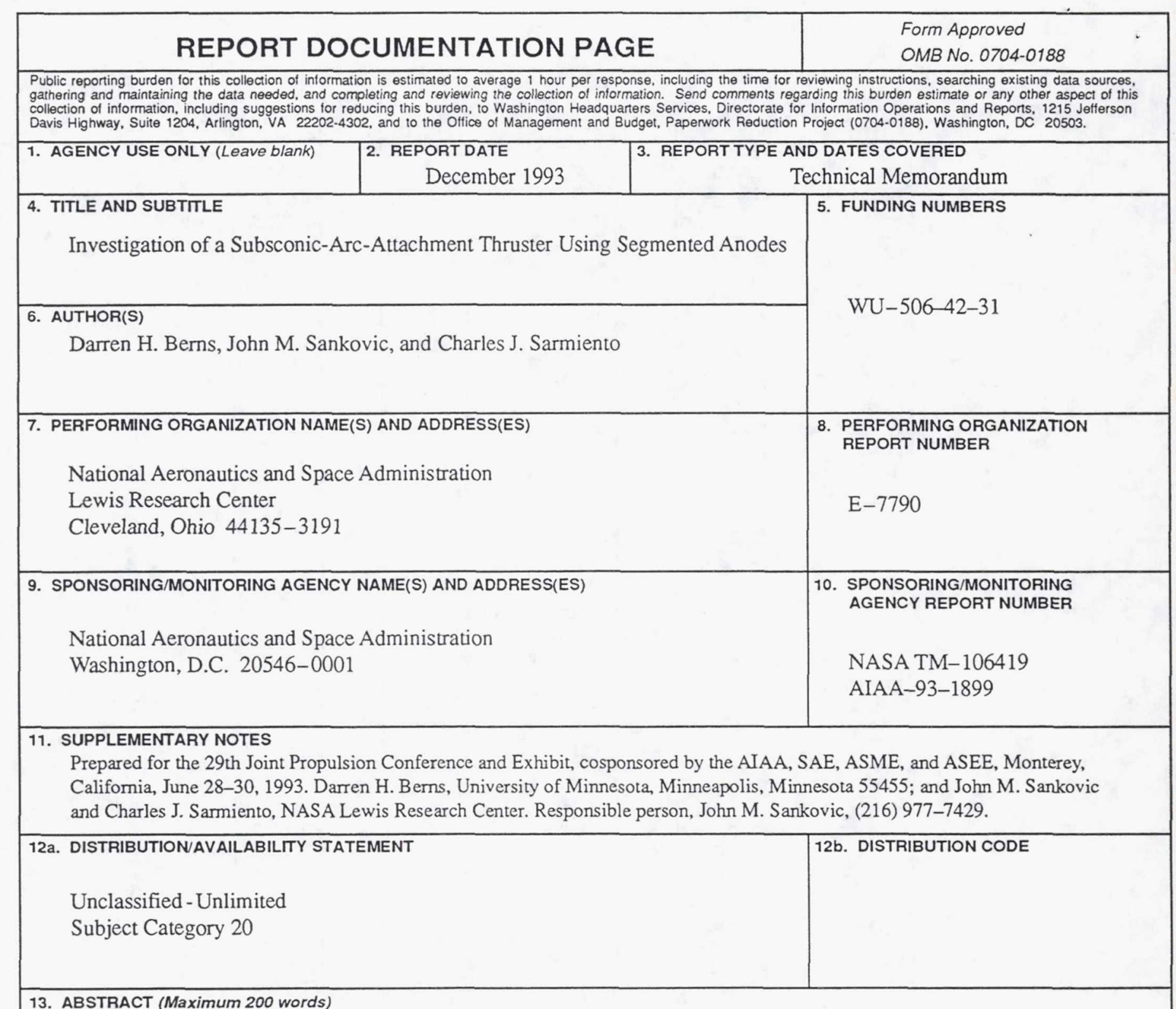

13. ABSTRACT (Maximum 200 words)

To investigate high frequency arc instabilities observed in subsonic-arc-attachment thrusters, a $3 \mathrm{~kW}$, segmented-anode arcjet was designed and tested using hydrogen as the propellant. The thruster nozzle geometry was scaled from a $30 \mathrm{~kW}$ design previously tested in the 1960's. By observing the current to each segment and the arc voltage, it was determined that the $75-200 \mathrm{kHz}$ instabilities were results of axial movements of the arc anode attachment point. The arc attachment point was fully contained in the subsonic portion of the nozzle for nearly all flow rates. The effects of isolating selected segments were investigated. In some cases, forcing the arc downstream caused the restrike to cease. Finally, decreasing the background pressure from $18 \mathrm{~Pa}$ to $0.05 \mathrm{~Pa}$ affected the pressure distribution in the nozzle, including the pressure in the subsonic arc chamber.

\begin{tabular}{|c|c|c|c|}
\hline \multirow{2}{*}{\multicolumn{3}{|c|}{$\begin{array}{l}\text { 14. SUBJECT TERMS } \\
\text { Electric propulsion; Arcjet thrusters; Arc instabilities }\end{array}$}} & \multirow{2}{*}{\begin{tabular}{|l|}
$\begin{array}{c}\text { 15. NUMBER OF PAGES } \\
24\end{array}$ \\
16. PRICE COPE \\
AO 3 \\
20. LIMITATION OF ABSTRACT
\end{tabular}} \\
\hline & & & \\
\hline $\begin{array}{l}\text { 17. SECURITY CLASSIFICATION } \\
\text { OF REPORT } \\
\text { Unclassified }\end{array}$ & $\begin{array}{l}\text { 18. SECURITY CLASSIFICATION } \\
\text { OF THIS PAGE } \\
\text { Unclassified }\end{array}$ & $\begin{array}{l}\text { 19. SECURITY CLASSIFICATION } \\
\text { OF ABSTRACT } \\
\text { Unclassified }\end{array}$ & 20. LIMITATION OF ABSTRACT \\
\hline \multicolumn{3}{|l|}{ NSN 7540-01-280-5500 } & $\begin{array}{l}\text { andard Form } 298 \text { (Rev. 2-89) } \\
\text { escribed by ANSI Std. Z39-18 } \\
8-102\end{array}$ \\
\hline
\end{tabular}


